\title{
Gut microbiota composition strongly correlates to peripheral insulin sensitivity in obese men but not in women
}

Citation for published version (APA):

Most, J., Goossens, G. H., Reijnders, D., Canfora, E. E., Penders, J., \& Blaak, E. E. (2017). Gut microbiota composition strongly correlates to peripheral insulin sensitivity in obese men but not in women. Beneficial Microbes, 8(4), 557-562. https://doi.org/10.3920/BM2016.0189

Document status and date:

Published: 01/01/2017

DOI:

10.3920/BM2016.0189

Document Version:

Accepted author manuscript (Peer reviewed / editorial board version)

Document license:

CC BY-NC-ND

Please check the document version of this publication:

- A submitted manuscript is the version of the article upon submission and before peer-review. There can be important differences between the submitted version and the official published version of record.

People interested in the research are advised to contact the author for the final version of the publication, or visit the DOI to the publisher's website.

- The final author version and the galley proof are versions of the publication after peer review.

- The final published version features the final layout of the paper including the volume, issue and page numbers.

Link to publication

\footnotetext{
General rights rights.

- You may freely distribute the URL identifying the publication in the public portal. please follow below link for the End User Agreement:

www.umlib.nl/taverne-license

Take down policy

If you believe that this document breaches copyright please contact us at:

repository@maastrichtuniversity.nl

providing details and we will investigate your claim.
}

Copyright and moral rights for the publications made accessible in the public portal are retained by the authors and/or other copyright owners and it is a condition of accessing publications that users recognise and abide by the legal requirements associated with these

- Users may download and print one copy of any publication from the public portal for the purpose of private study or research.

- You may not further distribute the material or use it for any profit-making activity or commercial gain

If the publication is distributed under the terms of Article $25 \mathrm{fa}$ of the Dutch Copyright Act, indicated by the "Taverne" license above, 


\section{Author's copy provided for non-commercial and educational use only}

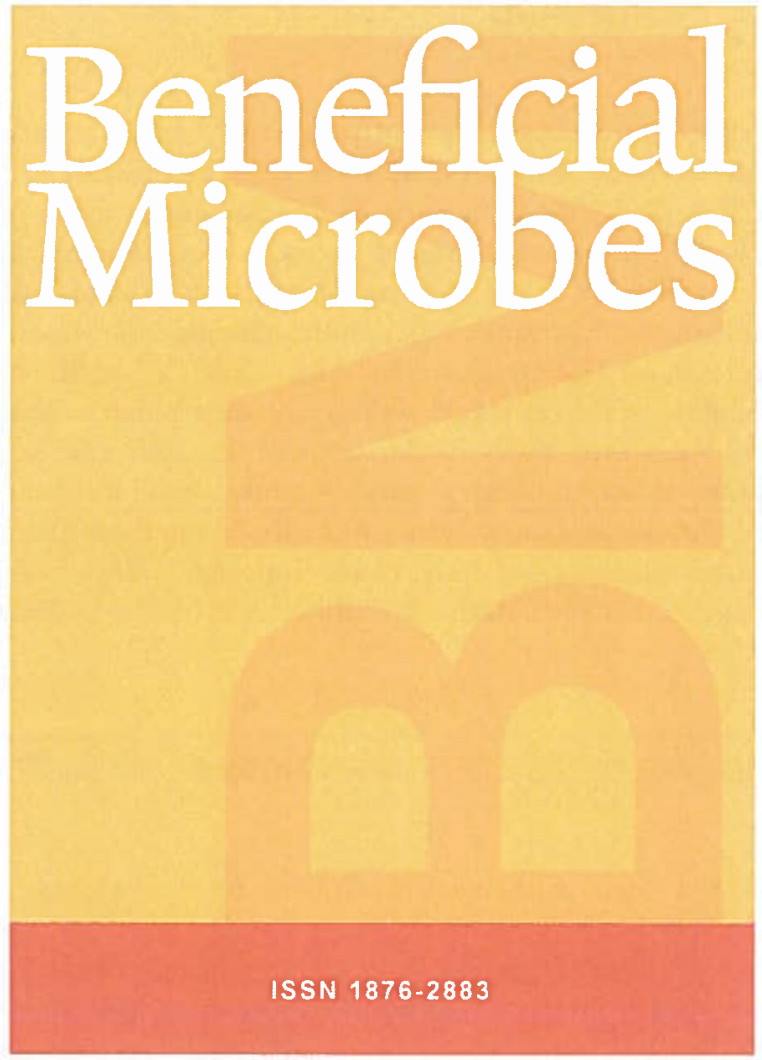

No material published in Beneficial Microbes may be reproduced without first obraining written permission from the publisher.

The author may send or transmit individual copies of this PDF of the article, to colleagues upon their specific request provided no fee is charged, and furtherprovided that there is no systematic distribution of the manuseript, e.g. posting on a listserve, website or automated delivery. However posting the article on a secure nerwork, not accessible to the public, is permitted.

For other purposes, e.g. publication on his/her own website, the author must use an author-created version of his/her article, provided acknowledgement is given to the original source of publication and a link is inserted to the published article on the

Beneficial Microbes website by referring to the DOI of the article.

For additional information please visit

www.BeneficialMicrobes.org. 


\section{Editor-in-chief}

Koen Venema, Beneficial Microbes Consultancy, Wageningen, the Netherlands

\section{Section editors}

- animal nutrition

- processing and application

- medical and health applications

- regulatory and safety aspects

- food, nutrition and health
Isaac Cann, University of Illinois at Urbana-Champaign, USA

Knut Heller, Max-Rubner-Institute, Germany

Ger Rijkers, Roosevelt Academy, the Netherlands

Mary Ellen Sanders, Dairy and Food Culture Technologies, USA

Koen Venema, Beneficial Microbes Consultancy, Wageningen, the

Netherlands

\section{Editors}

Alojz Bomba, Pavol Jozef Şafárik University, Slovakia; Yuliya Borre, Utrecht University, the Netherlands; RobertJan Brummer, Örebro University, Sweden; Michael Chikindas, Rutgers University, USA; James Dekker, Fonterra Co-operative Group, New Zealand; Leon Dicks, University of Stellenbosch, South Africa; Ana Paula do Carmo, Universidade Federal de Viçosa, Brazil; Margareth Dohnalek, PepsiCo, USA; George C. Fahey, Jr., University of Illinois, USA; Benedicte Flambard, Chr. Hansen, Denmark; Melanie Gareau, University of California San Diego, USA; H. Rex Gaskins, University of Illinois at Urbana-Champaign, USA; Audrey Gueniche, L'Oreal, France; Dirk Haller, Technical University München, Germany; Arland Hotchkiss, USDA-ARS, ERRC, USA; Sin-Hyeog Im, Pohang University of Science and 'Technology, Republic of Korea; David Keller, Ganeden Biotech, USA; Dietrich Knorr, Technical University Berlin, Germany; Lee Yuan Kun, National University of Singapore, Singapore; Irene Lenoir-IVijnkoop, Danone research, France; Takahiro Matsuki, Yakult Central Institute, Japan; Baltasar Mayo, CSIC, Spain; Eveliina Myllyluoma, Valio Ltd., Finland; Jiro Nakayama, Kyushu Univetsity, Japan; Peter Olesen, ActiFoods ApS, Denmark; Maria Rescigno, European Institute of Oncology, Italy; David Topping, CSIRO I Human Nutrition, Australia; Roel Vonk, University of Groningen, the Netherlands; Barbara Williams, University of Queensland, Australia; Zhongtang Yu, The Ohio State University, USA

\section{Founding editors:}

Daniel Barug, Bastiaanse Communication, the Netherlands; Helena Bastiaanse, Bastiaanse Communication, the Netherlands

\section{Publication information}

Bencficial Microbes: ISSN 1876-2883 (paper edition); ISSN 1876-2891 (online edition)

Subscription to 'Benelicial Miciobes' (4 issues, calendar year) is either on an institutional (campus) basis or a personal basis. Subscriptions can be online only, printed copy, or both. Prices are available upon request from the Publisher or from the journal's website (www. BeneficialMicrobes.org). Subscriptions are accepted on a prepaid basis only and are entered on a calendar year basis. Subscriptions will be renewed automatically unless a notilication of cancelation has been received before the $1^{\text {st }}$ of December. Issues are send by standard mail. Claims for missing issues should be made within six months of the date of dispatch.

Further information about the journal is available through the website www. BeneficialMicrobes.org.

\section{Paper submission}

http://mc.manuscriptcentral.com/bm

\section{Editorial office}

Wageningen Academic Publishers

P.O. Box 220

$6700 \mathrm{AE}$ Wageningen

'The Netherlands

Tel: +31317476516

Fax: +31317453417

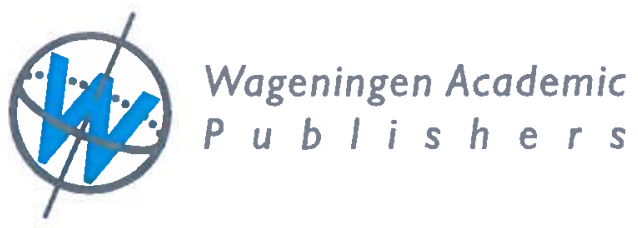

For questions related to paper submission: editorial@WorldMycotoxinJournal.org

For questions related to orders, claims and back volumes: subscription@WorldMycotoxinJournal.org 


\title{
Gut microbiota composition strongly correlates to peripheral insulin sensitivity in
} obese men but not in women

\author{
J. Most ${ }^{1}$, G.H. Goossens ${ }^{1}$, D. Reijnders ${ }^{1}$, E.E. Canfora ${ }^{1}$, J. Penders ${ }^{2}$ and E.E. Blaak ${ }^{1}{ }^{*}$ \\ 'Department of Human Biology, NUTRIM School of Nutrition and Translational Research in Metabolism, Maastricht \\ University Medical Center+, P.O. Box 616, 6200 MD Maastricht, the Netherlands; ${ }^{2}$ Department of Medical Microbiology, \\ NUTRIM School of Nutrition and Translational Research in Metabolism, Maastricht University Medical Center+, P.O. \\ Box 616,6200 MD Maastricht, the Netherlands; e.blaak@maastrichtuniversity.nl
}

Received: 1 November 2016 / Accepted: 26 March 2017

(c) 2017 Wageningen Academic Publishers

RESEARCH ARTICLE

\begin{abstract}
Gut microbiota composition may play an important role in the development of obesity-related comorbidities. However, only few studies have investigated gender-differences in microbiota composition and gender-specific associations between microbiota or microbial products and insulin sensitivity. Insulin sensitivity (hyperinsulinemic-euglycemic clamp), body composition (dual energy X-ray absorptiometry), substrate oxidation (indirect calorimetry), systemic inflammatory markers and microbiota composition (PCR) were determined in male $(n=15)$ and female $(n=14)$ overweight and obese subjects. Bacteroidetes/Firnicutes-ratio was higher in men than in women $(P=0.001)$. Bacteroidetes/Firmicutes-ratio was inversely related to peripheral insulin sensitivity only in men (men: $P=0.003$, women: $P=0.882$ ). This association between Bacteroidetes/Firmicutes-ratio and peripheral insulin sensitivity did not change after adjustment for dietary fibre and saturated fat intake, body composition, fat oxidation and markers of inflammation. Bacteroidetes/Firmicutes-ratio was not associated with hepatic insulin sensitivity. Men and women differ in microbiota composition and its impact on insulin sensitivity, implying that women might be less sensitive to gut microbiota-induced metabolic aberrations than men. This trial was registered at clinicaltrials.gov as NCT02381145.
\end{abstract}

Keywords: insulin sensitivity, Bacteroidetes, Firmicutes, obesity, fat oxidation, gender

\section{Introduction}

Gut microbiota dysbiosis has been associated with metabolic impairments, such as dyslipidemia and reduced insulin sensitivity in obese, non-diabetic subjects (Le Chatelier et al., 2013). In obese humans, lower ratios of the two dominant phyla of intestinal bacteria, Bacteroidetes and Firmicutes, have been found (Ley et al., 2006; Schwiertz et al., 2010; Turnbaugh et al., 2009; Verdam et al., 2013), yet a recent meta-analysis has found no significant association between the ratio (or individual phyla) and obesity status (Sze and Schloss, 2016).

Contrary to the relation with obesity, the Bacteroidetes/ Firmicutes-ratio has been reported to be associated with elevated glucose concentrations after an overnight fast and during an oral glucose tolerance test in diagnosed diabetic patients as compared to healthy volunteers in some (Larsen et al., 2010; Remely et al., 2013), but not all studies (Zhang et al., 2013). The glucometabolic status should therefore be considered when developing strategies to control metabolic diseases such as obesity by modifying the gut microbiota.

In more recent studies (Reijnders et al., 2016; Vrieze t al., 2012, 2014), detailed characterisation of tissue-specific insulin sensitivity by means of hyperinsulinemic-euglycemic clamp has been performed before and after modulation of microbial composition by means of antibiotics-intervention or after faecal transplantation in subjects with the metabolic syndrome. To distinguish between hepatic and peripheral insulin sensitivity may provide new insight in the relationship between the gut microbiota and metabolic health because both may be affected through different metabolic pathways (Scheithauer et al., 2016). In fact, the 
former study showed that microbial composition changes affected had more pronounced effects on peripheral as compared to hepatic insulin sensitivity (Vrieze et al., 2014). In addition, gender differences have not been taken into account in these studies. Noteworthy, the susceptibility to obesity and related co-morbidities after induction of microbial dysbiosis may be different in males and females (Cox et al., 2014; Murphy et al., 2014). For example, a significant interaction between early life antibiotic use and childhood body mass index (BMI) has been found for boys, but not for girls (Murplyy ct al., 2014), and alterations in the microbiota led to more pronounced increases in hepatic steatosis in males as compared to females (Cox ct al., 2014).

Here, we analysed cross-sectional clata on gender-related differences in microbiota composition and its relation with host metabolic phenotype, including tissue-specific insulin sensitivity, substrate oxidation and body composition in overweight and obese, non-diabetic Caucasian men ( $n=15)$ and women $(n=14)$.

\section{Materials and methods}

Analysed data were baseline measurements from subjects that were recruited for a 12-week polyphenolsupplementation study (Most et al., 2016), in which effects on insulin sensitivity (primary outcome), substrate oxidation and microbiota composition (secondary outcomes) were assessed. This ancillary paper will not discuss the primary outcomes of the polyphenol-intervention study, but will focus on the association between gender, microbiota composition and insulin sensitivity. Participants were recruited within the vicinity of the study centre at Maastricht University, were sedentary $(<3 \mathrm{~h} /$ week in sports activities) and had no cardiometabolic or gastrointestinal complications or diseases. Subjects had been weightstable and completed a detailed medical and lifestyle questionnaire, had not taken antibiotics or medication that may interfere with study outcomes for at least three months prior to enrollment.

We assessed insulin sensitivity by combining a twostep hyperinsulinemic-euglycemic clamp with stableisotope $\left[6,6-{ }^{2} \mathrm{H}_{2}\right]$-glucose tracer-infusion (Cambridge Isotope Laboratories, Andover, MA, USA). This enabled determination of peripheral and hepatic insulin sensitivity, expressed as insulin-stimulated rate of disappearance (Rd, $\mu \mathrm{M} /(\mathrm{kg} \times \mathrm{min}))$ at an infusion-rate of $40 \mathrm{mU} /\left(\mathrm{m}^{2} \times \mathrm{min}\right)$ and suppression of endogenous glucose production (suppression EGP, \%) at $10 \mathrm{mU} /\left(\mathrm{m}^{2} \times \mathrm{min}\right)$, respectively.

Faecal samples were collected at the study centre during one of the three visits before the intervention (Most et al., 2016). Samples were scooped into collection vials and inmediately frozen in liquid nitrogen at $-80^{\circ} \mathrm{C}$ until further analysis. For enumeration of selected bacterial groups, metagenomic
DNA was extracted and subjected to PCR assays targeting the major bacterial phyla (Applied Biosystems, Waltham, MA, USA). To extract DNA, approximately $200 \mathrm{mg}$ faeces was added to a $2 \mathrm{ml}$ vial containing approximately $500 \mathrm{mg}$ of zirconia beads $(0.1 \mathrm{~mm})$ and 4 glass beads $(3 \mathrm{~mm})$ and $1.2 \mathrm{ml}$ of lysis buffer P from the PSP SPIN Stool DNA kit (Stractec Biomedical, Berlin, Germany). Samples were treated in a Magna Lyser at $5.5 \mathrm{~ms}$ in 3 cycles of $1 \mathrm{~min}$ and cooled on ice in between cycli. Subsequently, the DNA isolation was continued using the PSP SPIN Stool DNA plus kit as per the manufacturer's instructions and finally eluted in $200 \mu$. For $\gamma$-Proteobacteria, Actinobacteria, Akkermansia muciniphila (phylum Verrucomicrobia) and Bacteroidetes, real-time detection of PCR-products was conducted with SYBR Green I (Bio-rad Laboratories Inc., Hercules, CA, USA) (Bacchetti de Gregoris et al., 2011; Collado et al., 2007). For Firmicutes, the 5 '-nuclease technique was used (ABgene, Hamburg, Germany) (Armougom et al., 2009). $\log _{10}$ DNA copies for a given microbial group/species per gram of wet weight faeces were calculated for each stool sample from the $\mathrm{Ct}$ values using standard curves that were constructed using serial diluted $\left(10^{1}-10^{7}\right.$ copies/PCR) recombinant plasmid constructs containing the amplicon of interest.

Dietary intake of macronutrient intake and saturated fat (all expressed as percentage of energy intake, \%EI) and fibre $(\mathrm{g} / \mathrm{MJ})$ were calculated from 3-day food records. An experienced dietitian checked the food records and discussed these with the subjects in case of incomplete or missing information. Energy and nutrient intakes were analysed by using the Dutch Food Composition dataset (NEVO; National Institute for Public Health and the Envitonment (RIVM), Bilthoven, the Netherlands). In addition, standardised meals were provided for the evenings prior to days of clinical assessments and sample collection. Body fat percentage was determined by dual energy X-ray absorptiometry (DXA, I lologic BCA; VitaK, Maastricht, the Netherlands) and waist and hip circumferences were measured using a non-expandable measuring tape midway between the lower rib margin and the iliac crest ('waist'), at largest circumference between the waist and the thighs ('hip') respectively. Energy expenditure (EE) and fat oxidation (expressed as percentage of EE, \%EE) was determined by means of indirect calorimetry (Omnical; Maastricht University, Maastricht, the Netherlands) in a half-supine position during fasting conditions and for $4 \mathrm{~h}$ postprandially (2.6 MJ, 61 energy\% fat) (Most et al, 2016). Fasting blood samples were taken for measurements of tumour necrosis factor- $x$ (I'NF- $x$ ) and interlcukin-6 (IL-6) using a multiplex ELISA (Human Prolnflammatory II 4-Plex Ultra-Sensitive Kit; Meso Scale Diagnositics, Rockville, MD, USA).

Gender differences were analysed by Students' unpaired $t$-test. All variables were tested for outliers and normal distribution (Shapiro-W/ilk). W/e performed regression 
analyses gender-specifically with insulin sensitivity as dependent and bacterial groups as independent variables, corrected for age (Model 1). Statistically significant relations were then subsequently adjusted for putative relevant covariates. Independent variables were included for food intake (FI, dietary saturated fat and fibre, Model $1+\mathrm{FI}$ ), body composition ( $\mathrm{BC}$, body fat percentage and distribution, Model $1+B C$ ), fat oxidation ( $F O$, fasting and postprandial, Model $1+\mathrm{FO}$ ) and systemic inflammatory markers (SIM, TNF- $\alpha$ and $[1,-6$, Model $1+$ SIM). TNF- $\alpha$ was In-transformed, because it was not normally distributed. Independent variables showed no inter-correlations (defined as $r>0.80$ ).

All subjects gave written informed consent before participation in this study, which was reviewed and approved by the local Medical Ethical Committee of Maastricht University Medical Centre ${ }^{+}$. All procedures were performed according to the declaration of Helsinki.

\section{Results}

We found higher copy numbers of $\gamma$-Proteobacteria and Bacteroidetes in men than women, while presence of other phyla were not different between gender (Table 1). Furthermore, the Bacteriodetes/Firmicutes (B/F)-ratio was significantly higher in men as compared to women $(P<0.001$, Table 1$)$.

Interestingly, a significant inverse linear association was found between the $\mathrm{B} / \mathrm{F}$-ratio and peripheral insulin sensitivity in men $(P=0.003$; Figure $1 \mathrm{~A})$ but not in women $(P=0.882$; Figure $1 B)$. No significant correlations were found between $B / F$-ratio and hepatic insulin sensitivity for both gender (Figure 1C-D). Specific phyla copy numbers ( $\gamma$-Proteobacteria, Actinobacteria, A. muciniphila, Bacteroidetes and Firmicutes) were not significantly correlated with any measure of insulin sensitivity in men or women (data not shown).

Macronutrient composition, dietary fibre and saturated fat intake (relative to energy intake) were comparable for men and women, while body fat percentage and distribution were different, as expected (Table 1). Of note, we found that food intake was not significantly altered throughout the 12 weekintervention that was initiated after the baseline assessments (data not shown). Based on this we are confident that food intake was similar before the intervention and well represented by the food intake records we collected. While fasting fat oxidation (\%energy expenditure, EE) and IL-6 were comparable between gender; postprandial fat oxidation (\%EE) and TNF- $u$ were higher in men vs women ('Table 1). Further adjustment for dietary fibre and saturated fat intake (Model $1+\mathrm{FI}$ ), body fat percentage and distribution (Model $1+\mathrm{BC}$ ), fasting and postprandial fat oxidation (Model $1+\mathrm{FO}$ ) and plasma intlammatory markers, 'INF- $\mathrm{x}$ and IL-6 (Model
$1+\mathrm{SIM})$ did not change the relation between $\mathrm{B} / \mathrm{F}-$ ratio and peripheral insulin sensitivity in men, as indicated by similar standardised beta-coefficients for the B/F-ratio in the models (Model 1: Std. $\beta(B / F-$ ratio) $=-0.71, P=0.005$; Model 1+FI: $-0.70,0.011$; Model 1+BC: $-0.79,0.004$; Model 1+FO: $-0.65,0.013$; Model 1+SIM: $-0.75,0.005$ ).

\section{Discussion}

The Bacteroidetes-content and the B/F-ratio were significantly higher in men as compared to women, which is in line with previous findings (Dominianni et al., 2015). Importantly, differences in ethnicity (Caucasian), age (20-50 years), BMI $\left(27-40 \mathrm{~kg} / \mathrm{m}^{2}\right)$ and regular exercise ( $<3 \mathrm{~h} /$ week) cannot explain these discrepancies, because groups were well-matched for these parameters in the present study. However, early life acquisition (delivery mode, breastfeeding status, use of antibiotics), lifestyle (local environment, eating and defecation pattern, exercise) and the hormonal environment may underlie the gender-specific microbiota composition.

Using the gold-standard hyperinsulinemic-euglycemic clamp method we found an inverse association of $B / F-$ ratio with peripheral insulin sensitivity, in men but not in women. Thus, the impact of microbiota on tissue-specific insulin sensitivity seems to differ between gender. Indeed, there is evidence for an increased gender-specific susceptibility to obesity and related co-morbidities after induction of microbial dysbiosis (Cox et al., 2014; Murphy et al., 2014). While no such information is available for adult humans yet, childhood obesity was significantly more associated to early life antibiotic exposure in boys than girls (5-8 years) after adjustment for several cofactors (Murphy et al., 2014). Likewise, the combination of antibiotic-treatment and high-fat diet, independently and synergistically, evoked alterations in microbial composition, increased obesity and hepatic steatosis, with all these effects being more pronounced in male than female mice (Cox et al., 2014). Of note, this detrimental phenotype was also observed after transfer of faecal microbiota from antibiotic-treated animals to germ-free mice, eliminating direct effects of antibiotic treatment itself. Finally, also gender-specific effects of diet on vertebrate's microbiota have been previously reported (Bolnick et al., 2014). Therefore, it is tempting to speculate that our gut microbiota may be involved as a determinant in differential gender-related metabolic responses to dietary interventions.

The inverse relationship between B/F-ratio and peripheral insulin sensitivity in men is consistent with a relative higher abundance of Bacteroidetes and deteriorated metabolic profile in non-diabetic subjects (Le Chatelier et al., 2013). Likewise, a reduction in Firmicutes and decreased peripheral insulin sensitivity was observed after antibiotictreatment in obese men with the metabolic syndrome 
Table 1. Subject characteristics (mean \pm standard deviation).

\begin{tabular}{|c|c|c|c|c|}
\hline \multicolumn{2}{|l|}{ Subject characteristics ${ }^{1}$} & $\operatorname{Men}(n=15)$ & Women $(n=14)$ & $P$-value ${ }^{2}$ \\
\hline \multirow{4}{*}{ Insulin sensitivity } & Age, yrs & $39.2 \pm 2.4$ & $35.1 \pm 3.0$ & 0.291 \\
\hline & $\mathrm{BMI}, \mathrm{kg} / \mathrm{m}^{2}$ & $29.4 \pm 0.7$ & $29.4 \pm 0.7$ & 0.992 \\
\hline & $\mathrm{Rd}, \mu \mathrm{M} /(\mathrm{kg} \times \mathrm{min})$ & $29.6 \pm 2.4$ & $35.6 \pm 3.2$ & 0.142 \\
\hline & EGP suppression, \% & $46.5 \pm 5.4$ & $68.4 \pm 3.3$ & 0.002 \\
\hline \multirow[t]{5}{*}{ Food intake } & Fibre, g/MJ & $1.8 \pm 0.1$ & $1.9 \pm 0.2$ & 0.741 \\
\hline & SFA, \%EI & $17.9 \pm 0.9$ & $16.8 \pm 0.8$ & 0.370 \\
\hline & Carbohydrate, \%EI & $43.9 \pm 1.6$ & $46.5 \pm 1.4$ & 0.239 \\
\hline & Protein, \%EI & $15.3 \pm 0.8$ & $15.4 \pm 0.8$ & 0.981 \\
\hline & Fat, \%El & $38.9 \pm 1.8$ & $36.0 \pm 1.3$ & 0.226 \\
\hline \multirow[t]{3}{*}{ Body composition } & Body fat, \% & $23.4 \pm 0.8$ & $37.0 \pm 1.0$ & $<0.001$ \\
\hline & WHR & $0.92 \pm 0.02$ & $0.79 \pm 0.01$ & $<0.001$ \\
\hline & Visceral fat, $\mathrm{g}$ & $500 \pm 45$ & $387 \pm 42$ & 0.080 \\
\hline \multirow[t]{2}{*}{ Fat oxidation } & Fasting, \%EE & $56.1 \pm 2.8$ & $54.7 \pm 3.8$ & 0.766 \\
\hline & Postprandial, \%EE & $52.5 \pm 2.7$ & $45.3 \pm 2.5$ & 0.057 \\
\hline \multirow[t]{2}{*}{ Systemic inflammation } & TNF-a, pg/ml & $3.49 \pm 0.22$ & $2.28 \pm 0.09$ & $<0.001$ \\
\hline & IL-6, pg/ml & $0.73 \pm 0.14$ & $0.93 \pm 0.17$ & 0.373 \\
\hline \multirow[t]{6}{*}{ Bacterial composition } & y-Proteobacteria, log & $11.3 \pm 0.1$ & $10.9 \pm 0.1$ & 0.028 \\
\hline & Actinobacteria, $\log$ & $11.5 \pm 0.1$ & $11.7 \pm 0.1$ & 0.345 \\
\hline & Akkemansia muciniphila, log & $8.7 \pm 0.5$ & $9.6 \pm 0.4$ & 0.186 \\
\hline & Firmicutes, log & $12.3 \pm 0.1$ & $12.4 \pm 0.1$ & 0.402 \\
\hline & Bacteroidefes, log & $13.2 \pm 0.1$ & $12.8 \pm 0.1$ & 0.001 \\
\hline & B/F-ratio & $10.13 \pm 1.66$ & $3.15 \pm 0.48$ & 0.001 \\
\hline
\end{tabular}

${ }^{1} \mathrm{BMl}=$ body mass index $\mathrm{Rd}=$ insulin-stimulated glucose rate of disappearance; $E G P=$ insulin-mediated suppression of endogenous glucose production; SFA = saturated falty acids; $E \mathrm{El}$ = total daily energy intake; WHR = waist-to-hip ratio; $E E$ = energy expenditure; TNF- $a=$ tumour necrosis factor-alpha; $: L-6$ $=$ interleukin $6 ; B / F$-ratio $=$ faecal Bacteroidetes/Firmicutes-ratio

${ }^{2}$ Statistical significance of Student's unpaired t-lest.

(V'ileze et al., 2014). Interestingly, in accordance with our findings, induced alterations in gut microbiota composition were paralleled by a reduction in peripheral, but not hepatic insulin sensitivity (Vrieze et al., 2014).

Several lifestyle and metabolic factors may mediate the relationship between $\mathrm{B} / \mathrm{F}$-ratio and insulin sensitivity (Khan ct al., 2014). Dietary fibre intake has been associated with beneficial effects on glucose metabolism, while high-fat diets were associated with reduced insulin sensitivity. A reduced bacterial diversity and altered microbial composition, induced by high-fat, low-fibre diets, may contribute to disturbances in substrate oxidation and insulin sensitivity by modulation of short-chain fatty acid (SCFA) and bile acid concentrations in the gut and circulation. Additionally, our microbiome may affect insulin sensitivity through induction of inflammatory and hormonal signals (lipopolysaccharides, respectively glucagon-like-peptide 1). Taken together, there appears to be a strong interaction between dietary factors, the microbial composition and impaired insulin sensitivity. Therefore, we investigated whether the relationship between the B/F-ratio and insulin sensitivity in men can, at least partly, be explained by lifestyle factors such as dietary fibre and saturated fat intake, or metabolic factors such as fat oxidation and lowgrade inflammation. Strikingly, adjustment for the abovementioned factors did not change the strong association between the B/F-ratio and peripheral insulin sensitivity in men, suggesting involvement of other factors.

It is beyond the scope of this study, which is associative in nature, to draw any conclusions on putative mechanisms responsible for the strong association between $\mathrm{B} / \mathrm{F}$-ratio and peripheral insulin sensitivity. However, our data clearly indicate that microbiome-host interactions should be taken into account in controlled intervention studies.

In conclusion, the present study demonstrated a significant difference in microbiota composition between men and women. Furthermore, we found a strong relationship between intestinal microbiota composition and peripheral, but not hepatic, insulin sensitivity in men but not in women, which remained unchanged after adjustment of dietary saturated fat and fibre intake, body composition, 

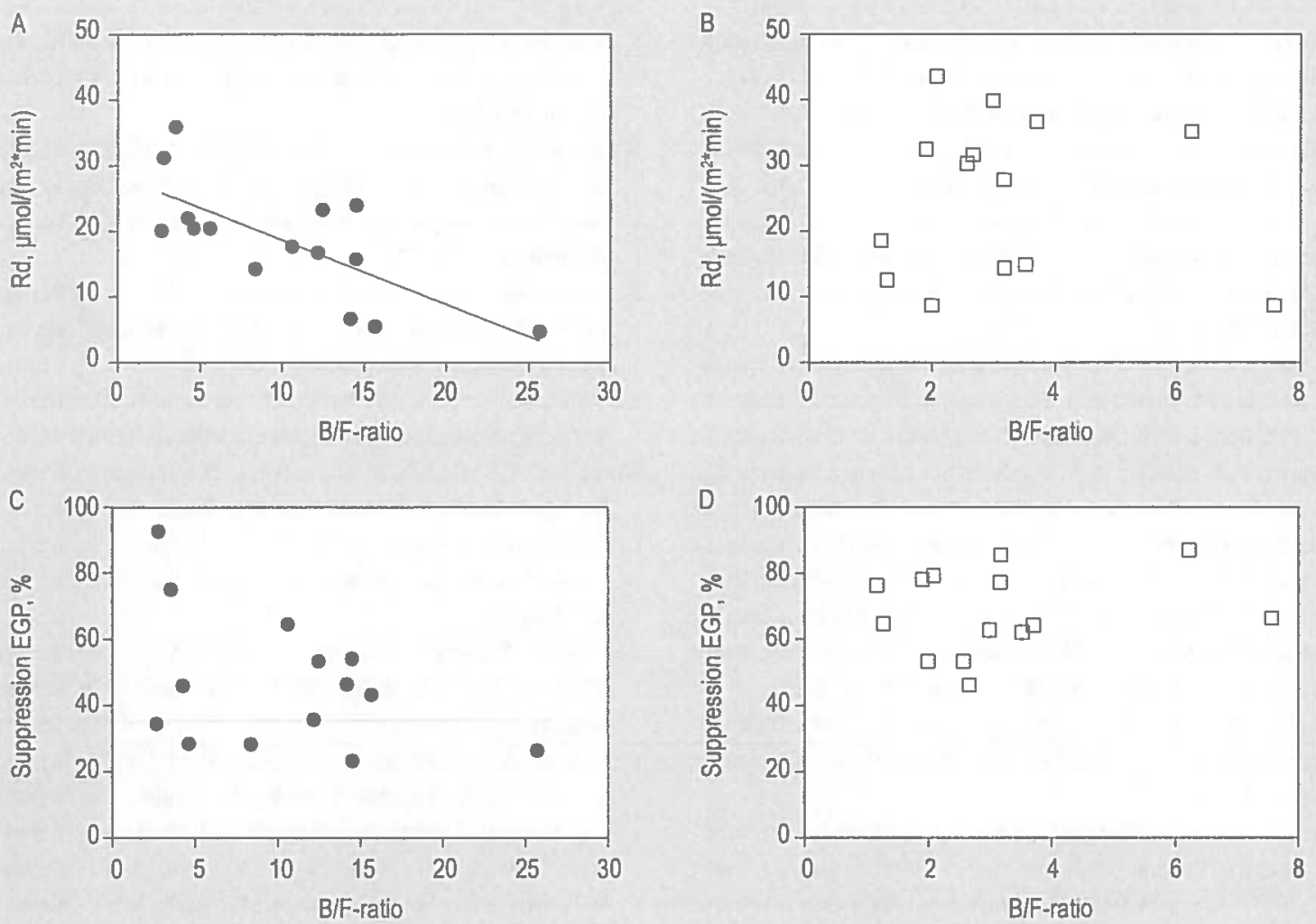

Figure 1. Relations between Bacteroidetes/Firmicutes-ratio (B/F-ratio) and insulin sensitivity by gender. B/F-ratio plotted against peripheral $(A, B)$ and hepatic $(C, D)$ insulin sensitivity of men $(A, C)$ and women $(B, D)$. Rd = insulin-stimulated glucose rate of disappearance; suppression EGP = insulin-mediated suppression of endogenous glucose production.

fat oxidation and systemic inflammation. Our findings are preliminary in nature and require confirmation in larger populations using state-of-the-art next generation sequencing. Understanding the aetiology of microbial dysbiosis, and elucidating how the microbiota impacts host metabolism in a gender-specific manner may open new avenues for the treatment of obesity-related cardiometabolic disorders.

\section{Acknowledgements}

The authors would like to thank the study participants, as well as Mayk Lucchesi and Wendy Sluijsmans for their excellent technical support. Ellen Blaak is the guarantor of this work and, as such, had full access to all the data in the study and takes responsibility for the integrity of the data and the accuracy of the data analysis. None of the authors have any conflict of interest to declare. This study was funded by the ALPRO foundation.

\section{References}

Armougom, F., Henry, M., Vialettes, B., Raccah, D. and Raoult, D., 2009. Monitoring bacterial community of human gut microbiota reveals an increase in Lactobacillus in obese patients and Methanogens in anorexic patients. PloS ONE 4: e7125.

Bacchetti De Gregoris, T., Aldred, N., Clare, A.S. and Burgess, I.G., 2011. Improvement of phylum- and class-specific primers for realtime PCR quantification of bacterial taxa. Journal of Microbiological Methods 86: 351-356.

Bolnick, D.I., Snowberg, L.K., Hirsch, P.E., Lauber, C.L., Org, E., Parks, B., Lusis, A.J., Knight, R., Caporaso, J.G. and Svanback, R. 2014. Individual diet has sex-dependent effects on vertebrate gut microbiota. Nature Communications 5: 4500 .

Collado, M.C., Derrien, M., Isolauri, E., De Vos, W.M. and Salminen, S., 2007. Intestinal integrity and Akkermansia muciniphila, a mucindegrading member of the intestinal microbiota present in infants, adults, and the elderly. Applied and Environmental Microbiology 73: 7767-7770.

Cox, L.M., Yamanishi, S., Sohn, J., Alekseyenko, A.V., Leung, J.M., Cho, I., Kim, S.G., Li, H., Gao, Z., Mahana, D., Zarate Rodriguez, J.G., Rogers, A.B., Robine, N., Loke, P. and Blaser, M..)., 2014. Altering the intestinal microbiota during a critical developmental window has lasting metabolic consequences. Cell 158: 705-721. 
Dominianni, C., Sinha, R., Goedert, J.J., Pei, Z., Yang, L., Hayes, R.B. and Ahn, I., 2015. Scx, body mass index, and dietary fiber intake influence the human gut microbiomc. PloS ONE 10: 0124599.

Khan, M.T., Nicuwdorp, M. and Backhed, F., 2014. Microbial modulation of insulin sensitivity. Cell Metabolism 20:753-760

Larsen, N., Vogensen, F.K., Van den Berg, F.W., Nielsen, D.S., Andreasen, A.S., Pedersen, B.K., Al-Soud, W.A., Sorensen, S.J., Hansen, L.H. and Jakobsen, M., 2010. Gut microbiuta in human adults with type 2 diabetes differs from non-diabetic adults. PloS ONE 5: e9085.

Le Chatelier, E., Nielsen, T., Qin, J., Prifti, E., Hildebrand, F, Falony, G., Almeida, Ml, Arumugam, M., Batto, I.M., Kennedy, S., Leonard, P., Li, J., Burgdorf, K., Grarup, N., Jorgensen, 1., Brandslund, l., Nielsen, H.B., Juncker, A.S., Bertalan, M., Levenez, F., Pons, N., Rasmussen, S., Sunagawa, S., Tap, I., Tims, S., Zoetendal, E.G Brunak, S., Clement, K., Dore, I., Kleerebezem, M., Kristiansen, K., Renault, P., Sicheritz-Ponten, T., De Vos, W.M., Zucker. I.D., Raes. 1., Hansen, 'T., MetaHIT consortium, Bork, P., Wang, I., Elrlich, S.D. and Pedersen, O, 2013. Richness of human gut microbiome corrclates with metabolic markers. Nature 500: 541-546.

Ley, R.E., 'lurnbaugh, P.I., Klein, S. and Gordon, J.1, 2006. Microbial ecology: human gut microbes associated with obesity. Nature 44.4: 1022-1023.

Must, I., Tïmmers, S., Warnke, 1., Jocken, J.W., Van Buekschoten, M., De Groot, P., Bendik, 1., Schrauwen, P., Goossens, G.H. and Blaak, E.E, 2016. Cumbined epigallocatechin-3-gallate and resveratrol supplementation for $12 \mathrm{wk}$ increases mitochondrial capacity and fat oxidation, but not insulin sensitivity, in obese humans: a randomized controlled trial. American Journal of Clinical Nutrition 104: 215-227.

Murphy, R., Stewart, A.W., Braithwaite, 1., Beasley, R., Hancox, R.J., Mitchell, E.A. and ISAAC Phase Three Study' Group, 2014. Antibiotic treatment during infancy and increased loody mass index in boys: an international cross-sectional study. Inturnational Journal of Obesity 38: 1115-1119.

Reijnders, D., Goossens, G.H., Hermes, G.D., Neis, E.P., Van der Beck, C.M., Mlost, I., Holst, I.J, Lenaerts, K., Kootte, R.S., Nieuwdorp, M., Groen, A.K., Olde Damink, S.W., Bockschoten, M.V., Smidt. H., Zoetendal, E.G. Dejong, C.H. and Blaak, E.E., 2016. Effects of gut microbiota manipulation by antibiotics on host metabolism in obesc humans: a randomized double-blind placebo-controlled trial. Cell Metabolism 24:64-74, 341 (correction).
Remely, M., Dworzak, S., Hippe, B., Zwielehner, I., Aumueller. E., Brath, H. and Haslberger, A.G., 2013. Abundance and diversity of microbiuta in Type 2 diabetes and obesity. Journal of Diabetes and Metabolism 4: 253

Scheithater, 1.P., Dallinga-Thic, G.M., De Vos, W.M., Nieuwdorp, M. and Van Raalte, D.H., 2016. Causality of small and large intestinal microbiota in weight regulation and insulin resistance. Molecular MIctabolism 5: 759-770.

Schwiertz, A., Taras, D., Schafer, K., Beijer, S., Bos, N.A., Donus, C. and Hardt, P.D., 2010. Microbiota and SCFA in lean and overweight healthy subjects. Obesity $18:$ 190-195.

S7c, M.A. and Schloss, P.D., 2016. Looking for a signal in the noise: revisiting obesity and the microbiome. MBio 7, c01018-16.

Turnbaugh, P.I., Hamady, M., Yatsunenko, T., Cantarel, B.L., Duncan, A, Ley, R.E., Sugin, M.L., Jones, W.J., Roe, B.A., Affourtit, J.P., Egholm, M., Henrissat, B., Heath, A.C., Knight, R. and Gordon, 1.1., 2009. A core gut microbiome in obese and lean twins. Nature 4.57: $180-484$

Verdam, F. J., Fuentes, S., De longe, C., Loctendal, E.G. Erbil. R., Greve, J.W., Beturman, W.A., De Vos, W.M. and Rensen. S.S., 2013. Human intestinal microbiota composition is associated with local and systemic inflammation in obesity. Olesity 21: $2607-615$.

Vricze, A., Out, C., Fuentes, S., Innker, L., Reuling, l., Kootte, R.S, Van Nood, E, Holleman, F, Knanpen, M, Romijn, J.A., Socters, M.R., Blaak, E.E., Dallinga-Thie, G.M., Reijnders, D., Ackermans, M.1., Serlic, M.J., Knop, F.K, Holst, J., Van der Ley, C., Kema, 1.P., Znetendal, E.G. De Vos, W.M.., Iockstra, J.B., Stroes, E.S., Groen, A.K. and Nieuwdorp, M, 2014. Impact of oral vancomycin on gut microbiota, bile acid metabolism, and insulin sensitivity. Journal of hicpatology 60: 824-831.

Vrieze, A., Van Nood, E., Holleman, l., Salojarvi, J., Kootte, R.S., Bartelsman, J.F., Dallinga Thic, G.M., Ackermans, M.I., Serlie, M.J., Oozeer, R., Derrien, M., Druesne, A., Van Hylckama Vlieg, J.E., Bloks, V.W., Groen, A.K., Heilig, H.G., Zoetendal, E.G. Stroes. ES., De Vos, W.M., Hoekstra, I.B. and Nieuwdorp, M., 2012. Transfer of intestinal microbiota from lean donors increases insulin sensitivity in individuals with metabolic syndrome. Gastroenterology 143: 913-916 e917.

Zhang, X., Shen, D., Fang, Z., lie, Z., Qiu, X., Zhang, C., Chen, Y. and Ji, L., 2013. Human gut microbiota changes reveal the progression of glucose intolerance. PloS ONE 8: e 71108 . 